\title{
The Early Stages of Nephrops norvegicus, from the Northumberland Plankton, together with a note on the post-larval development of Homarus vulgaris.
}

\author{
By \\ Olga M. Jorgensen, M.Sc.,
}

Dove Marine Laboratory, Cullercoats.

With Plates I to II and 1 Chart in the Text.

'Although adult Norway lobsters are extremely common on the southern part of the Northumberland coast, there were no records of the taking of larvæ of the species in this part of the North Sea until the Plankton Investigation now being carried out at Cullercoats (1) was commenced.

During the period 1921-23 a few specimens were taken from time to time in the ordinary plankton hauls, but the best catches of Nephrops larvæ were obtained from the young fish trawl used at a number of stations in 1922 and 1923. It is, therefore, chiefly on the material from the last two years' samples that the following observations are based.

All three of the larval stages have been obtained, together with a single post-larva, but the majority of our specimens are second and third stage larvæ.

\section{First Stage Larve.}

The newly hatched larva is a zoea (2), with the first thirteen pairs of appendages fully developed (Plate I, Fig. 1). The first abdominal segment is entirely hidden beneath the carapace, and both it and the following one are devoid of dorsal spines. The third segment bears a short but distinct dorsal spine, measuring about one-sixth of the length of that on the following segment.

In all the three stages our larvæ differ from that figured by Sars (3), in having a spine on the third abdominal segment, and also in having a much larger spine in the angle of the caudal fork. There is a small protuberance on the third abdominal segment in one of Sars' figures, which makes it probable that his specimen was damaged.

The rostrum, in the first larval stage, is entirely devoid of armature, and the supra-ocular spines, present in the next stage, have not, as yet, made their appearance. The great claws and the two following pairs 
of appendages are already chelate, and all five pairs of pereiopods bear exopodites. Towards the end of the first instar the appendages of the . second to the fifth abdominal segments can be seen as small buds beneath the cuticle of the next stage.

The length of this stage, measured from the tip of the rostrum to the angle of the caudal fork, is about $6.5 \mathrm{~mm}$.

\section{Second Stage Larve.}

The appendages of the second to the fifth abdominal segments are now present as small biramous structures, but there is no sign of the appendages of the first segment. The segments of the antennæ are more fully differentiated than they were in the previous stage, and the large supraocular spines have appeared (Plate I, Fig. 2). As the second ecdysis approaches the developing uropods can be seen beneath the new cuticle in front of the caudal fork, which is still not differentiated from the last abdominal segment.

This stage is accurately figured by Sars, except as regards the spines mentioned in the description of Stage I, above.

The average length of Stage II larvæ is $8 \mathrm{~mm}$.

\section{Third Stage Larve.}

When the third and last larval stage is reached the pleopods of the second to the fifth abdominal segments are fully developed, as are also the uropods, but the first abdominal segment is still devoid of appendages (Plate I, Fig. 3). The rostrum now bears three pairs of teeth dorsolaterally and the caudal fork is segmented off from the last abdominal segment. This stage is accurately figured by Sars, again with the exception of the dorsal abdominal spines. His figure shows the long spines on segments 3 and 5 instead of on 4 and 5 .

This stage measures $10 \mathrm{~mm}$. in length.

\section{First Post-larval Stage.}

On reaching the first post-larval stage the creature no longer possesses the long spines, the caudal fork, nor the exopodites of the pereiopods, and assumes, in general; the characters of the adult (Plate II, Fig. 1).

The rostrum has now four pairs of dorso-lateral teeth and a single ventral tooth near the tip. Groups of setæ are present on various parts of the carapace, and small protuberances, the precursors of teeth present on the cardiac region in later stages, are now visible.

The endopodite of the second antenna has now elongated to become the flagellum, and the whole appendage has the characteristic form of the adult structure. The telson also approximates to the adult form 
(Plate II, Fig. 2), and the sculpturing on the terga of the abdominal segments is beginning to make its appearance.

The uropods differ from those of the adult in that the exopodite is not yet divided; but remains, as in the previous stage, a simple, oval plate.

It is interesting to note that the first abdominal segment is still devoid of appendages, and it would appear that the development of the first pair of pleopods, which are modified in connection with the reproductive function, is correlated with that of the gonads. It will be necessary, however, to examine later stages, not at present available, before it is possible to say at which stage the appendages appear and how far this supposition holds good.

At the ecdysis which changes the larva into the young adult the creature seems to direct all its energies towards the production of the new form, and to concern itself little, if at all, with growth. A first post-larval stage measured from the tip of the rostrum to the distal end of the telson had a length of $11 \mathrm{~mm}$., or only $1 \mathrm{~mm}$. longer than the average length of the Stage III larva.

\section{Distribution of the Northumberland Larve.}

Maps showing the stations worked and tables giving the date and other particulars concerning the plankton samples are given in the Dove Marine Laboratory Reports for 1923 (4) and 1924 (5), as are also tables giving similar information with regard to catches of the species under consideration (6). It is from these data that the chart showing the distribution of Nephrops larvæ in our district has been drawn up.

It would appear that the larvæ can be divided into three distinct groups: (1) those which are hatched on our local "prawn" ground; (2) those which come from the ground to the north of us, in the region of the Firth of Forth; and (3) some few which must have been freed still farther north.

Taking into consideration the three years' catches, the following facts are outstanding. Early in the season (May and June), Stage I larvæ were present in the southern region (marked A on chart). In August young larvæ, chiefly Stage I, were taken at the extreme north, in the Burnmouth-Berwick region, and a little further south samples contained a preponderance of Stage II. Hauls made about the same time in the southern area included only Stage III, and a first post-larval stage (B). The catches from the northern stations included also at this time a few old larvæ (C).

It will be seen from the chart that no samples were taken in the Burnmouth district in May and June, at the time when the first larvæ were obtained further south, so that we do not know when the Firth of Forth 
larvæ first reach the Northumberland coast, but from the fact that in Group B we have Stage I off Burnmouth and the first post-larval stage off Newbiggin at the same time, the larvæ must have been drifting along the coast for some weeks. It is evident that they continue to arrive from May or early June until about the end of August.

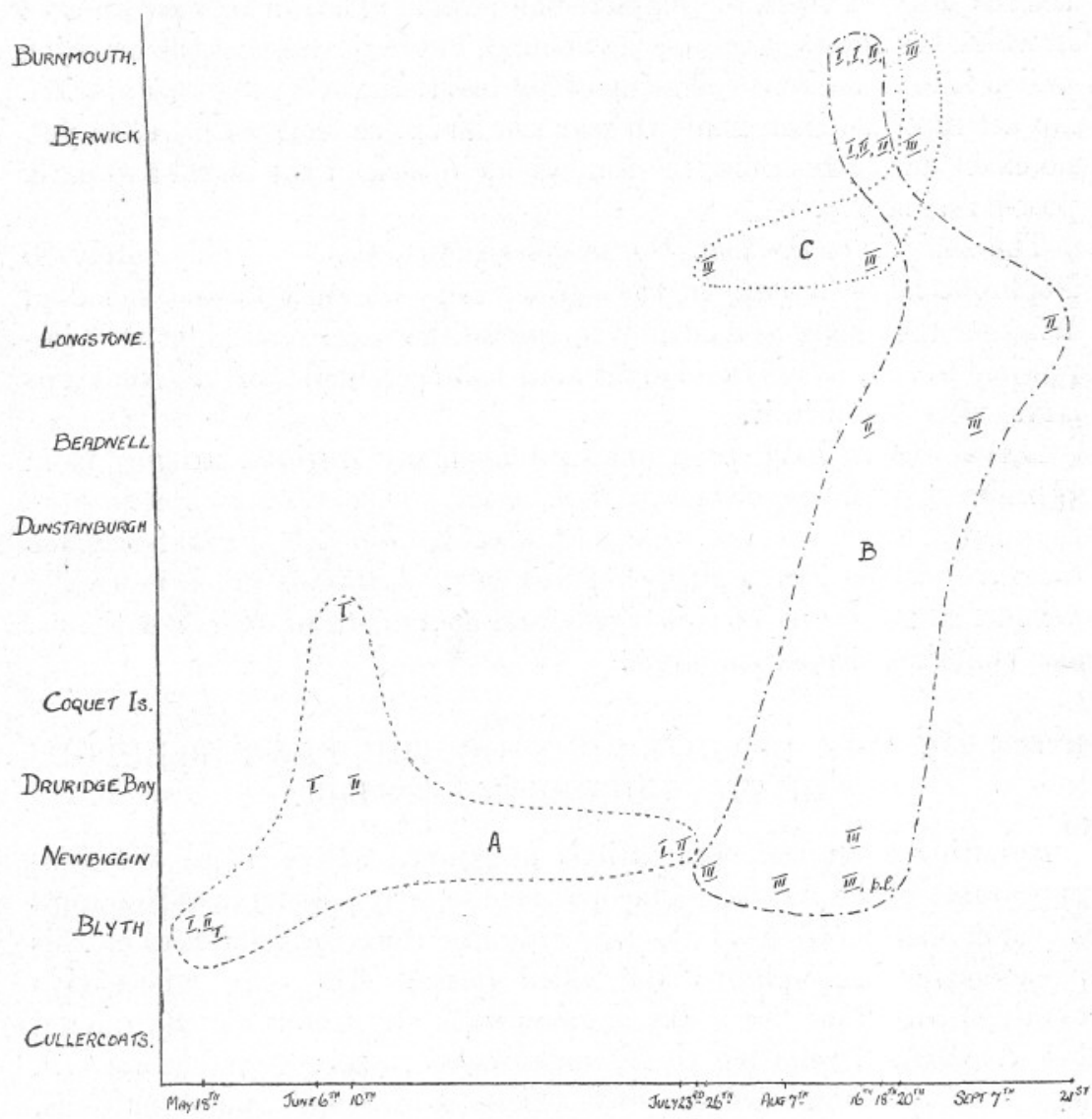

Chart showing the three groups of Nephrops larvæ obtained off the Northumberland coast during 1921-23.

Of the three groups of larvæ, only the second, B, is of importance to us from the point of view of the re-stocking of our local " prawn " ground, as those in A leave the district in Stages I or II, and those in C evidently do not really belong to our district at all, but appear to be stragglers from the stock of larvæ which, hatched still farther north than those of Group B, normally arrive at the end of the larval period in the Firth of Forth region. Whether these larvæ appear annually in the Berwick 
district, or stray so far south only occasionally remains to be seen when further samples are examined.

Although we want more data before a complete account of the development of Nephrops can be given, the examination of our material shows not only the drift of the larvæ from north to south, and a tendency for the majority of them to complete the pelagic phase in or near an area in which the adults of the species abound, but indicates that the hatching period is to be reckoned as being of not less than three months' duration. No attempt has been made to rear the larvæ, so that we have, as yet, no exact data concerning the time spent in each of the larval and early post-larval stages.

The analysis of the plankton samples shows, also, that only rarely do Nephrops larvæ appear in the surface nets, at least during the day. Whether they show a tendency to rise to the surface at night it is impossible to say, as only one night haul has been made and no Nephrops larvæ were taken in it.

Larval stages have been obtained at many stations, ranging from $1 \frac{1}{2}$ miles to 10 miles offshore, but none have been taken nearer inshore than this. That is to say, that with one exception all our material was taken in water of from 20 to $37 \frac{1}{2}$ fathoms. A sample taken unusually far out, 12 miles east of Newbiggin, and at a depth of over 50 fathoms, also contained Nephrops larvæ.

\section{NOTE ON THE DEVELOPMENT OF THE FIRST PLEOPODS OF THE EUROPEAN LOBSTER.}

Resulting from the observations mentioned above as to the nonappearance of the first pair of pleopods in the early post-larva of Nephrops a search was made in all the available literature for references to this phenomenon in Nephrops and allied forms. The only information obtained was from the works of Barnes ( $\mathbf{y})$ and Chadwick (8), quoted below. Barnes, referring to $H$. americanus, states: "At the seventh stage the appendages of the first abdominal segment appear as buds, and by the eighth stage they have developed sufficiently to enable the sex to be told." Chadwick says of $H$. vulgaris that: "After further ecdyses (no size or stage given) ... the appendages of the first abdominal segment develop. They are at first of similar form in the two sexes, but acquire sexual characters at a later stage."

With a view to gaining some more definite information on this point, a number of preserved specimens of young lobsters were examined, and even from this rather scanty material (all the specimens are females), it is possible to make out one or two features of interest.

The smallest specimen which bore any indication of the first pair of 
pleopods was one which measured $3.5 \mathrm{~cm}$. in length. A careful examination of the sternite of the first abdominal segment of this specimen revealed a pair of very small, blunt processes lying towards the posterior border, closely pressed against the sternite and with their distal ends towards the mid-ventral line (Plate II, Fig. 3). Specimens, measuring from $4 \cdot 0 \mathrm{~cm}$. to $5 \cdot 3 \mathrm{~cm}$., had the appendages present as a pair of straight, undivided rods about $2.5 \mathrm{~mm}$. in length, and with a few small setæ near the tip (Plate II, Fig. 4), whilst those in the next stage, $6 \cdot 0 \mathrm{~cm}$. to $7 \cdot 3 \mathrm{~cm}$. long, bore pleopods on the first abdominal segment about $5 \mathrm{~mm}$. in length, and having a definite resemblance to the adult female appendage. They still remained undivided into protopodite and endopodite, but were flattened and bore about twelve long plumose setæ on either border, along the distal half of its length (Plate II, Fig. 5). In a specimen $9 \cdot 0 \mathrm{~cm}$. long the development of the first pleopods was practically complete, the short, broad protopodite being distinct from the long, thin endopodite which now bore about twenty setæ on each side (Plate II, Fig. 6). Only the addition of more setæ as the organ increases in size is required for the attainment of the adult female form.

From a consideration of the statistics relating to size and age given by Meek $(\mathbf{9}, \mathbf{1 0})$, it would appear that the initial stage in the development of the first pleopods of the European lobster occurs when the creature is from three to six months old, or in about the tenth stage; that the half-grown condition of the same appendages is attained at the age of six to twelve months; and that the fully grown but unsegmented organ is produced in the second year, and the perfect appendages, in the female at least, after that time-in about the thirteenth stage.

It is of interest to note also that the figures given for the Northumberland lobsters bear a very close relation to those of Waddington (11), particularly if it be borne in mind that his "tame" lobster was reared under conditions which tended to retard the normal rate of growth.

So far then as we are able to judge from the limited material available, the development of the first pair of pleopods in $H$. vulgaris is completed in four stages, beginning when the animal is about six months old and extending over four instars (probably the tenth to the thirteenth), and being completed only when the creature has attained the age of, at least, two years.

\section{REFERENCES TO LITERATURE.}

1. Meek, A. "Plankton Investigations." Dove Marine Laboratory Report, New Series, XII, 1923.

2. Меeк, A. "On the Crustacea. Larval Nomenclature." Dove Marine Laboratory Report, New Series, VII, 1918. 
3. SArs, G. O. Archiv. f. Mathem. og Naturvidenskab, Bd. 9, 1884, and Bd. 13, 1889.

4. Meer, A. Dove Marine Laboratory Report, New Series, XII, pp. $70-72$.

5. Meek, A. Dove Marine Laboratory Report, New Series, XIII, pp. $51-52$.

6. Jorgensen, O. M. Dove Marine Laboratory Report, New Series, XII, p. 123 ; XIII, p. 73 and pp. 88-89.

7. Barnes, E. W. 41st Ann. Rep. Comm. Inland Fisheries of Rhode Island, 1910.

8. Chadwick, H. C. Lancashire Sea Fisheries Rep., 1904.

9. Meek, A. "Lobster Culture." Northumberland Sea Fisheries Comm. Rep., 1904.

10. Meek, A. "Lobster Culture." Northumberland Sea Fisheries Comm. Rep., 1911.

11. Waddington, H. J. Southern Sea Fisheries Comm. Rep., 1910-11 and 1911-12.

\section{EXPLANATION OF PLATES.}

PLATE I.

Fig. 1. Stage I, larva of Nephrops, from the left side.

,2. Stage II, larva of Nephrops, from the left side.

, 3. Stage III, larva of Nephrops, from the left side. 


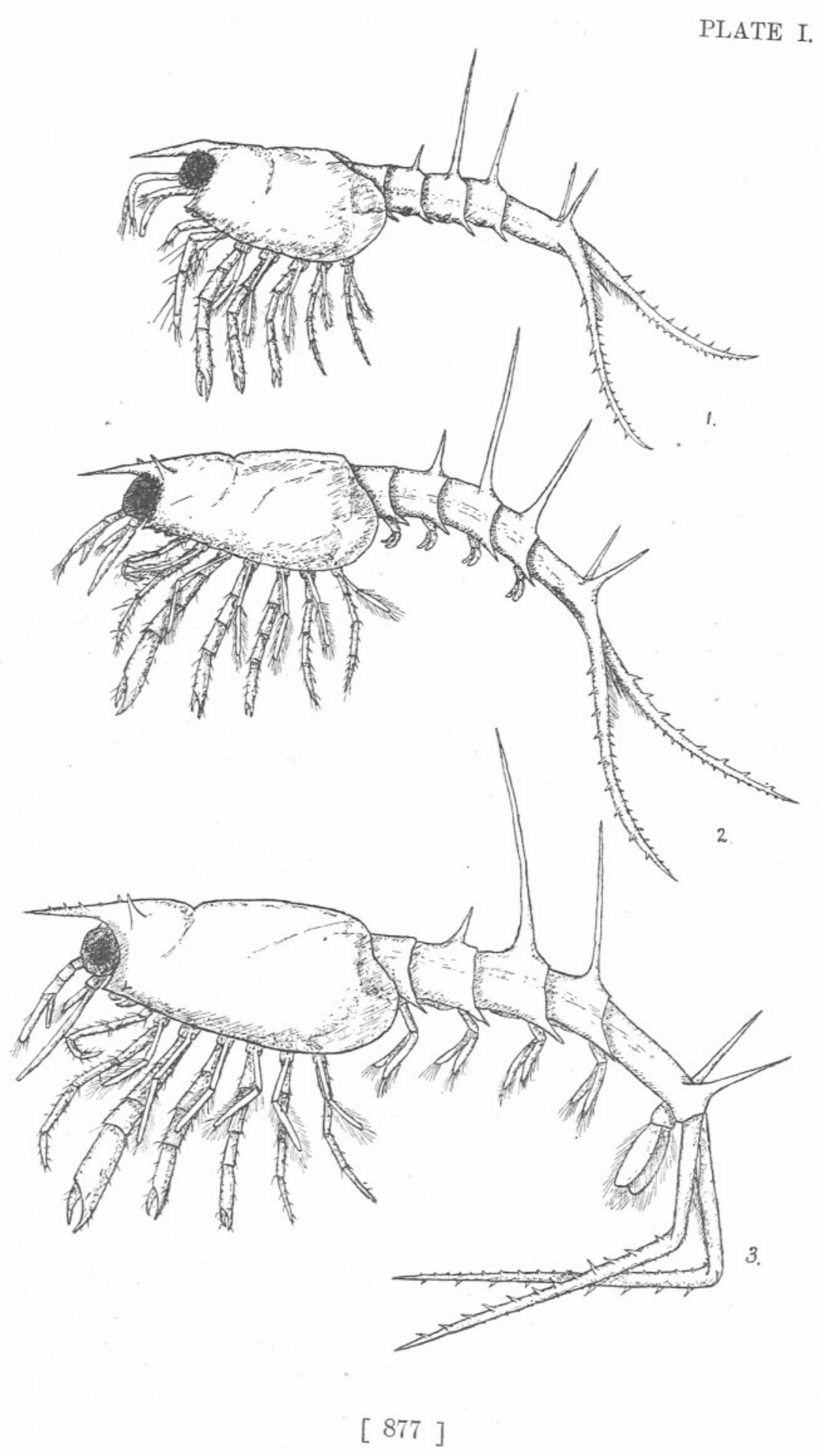




\section{PLATE II.}

Frg. 1. First post-larval stage of Nephrops, from the left side.

", 2. First post-larval stage of Nephrops, telson and uropods, from the ventra! aspect.

, 3 Sternite of first abdominal segment of Homarus vulgaris, showing first stage in development of the first pair of pleopods.

, 4-6. Anterior end of abdomen of $H$. vulgaris, from the left side, showing the later stages in the development of the same appendages. 
PLATE II

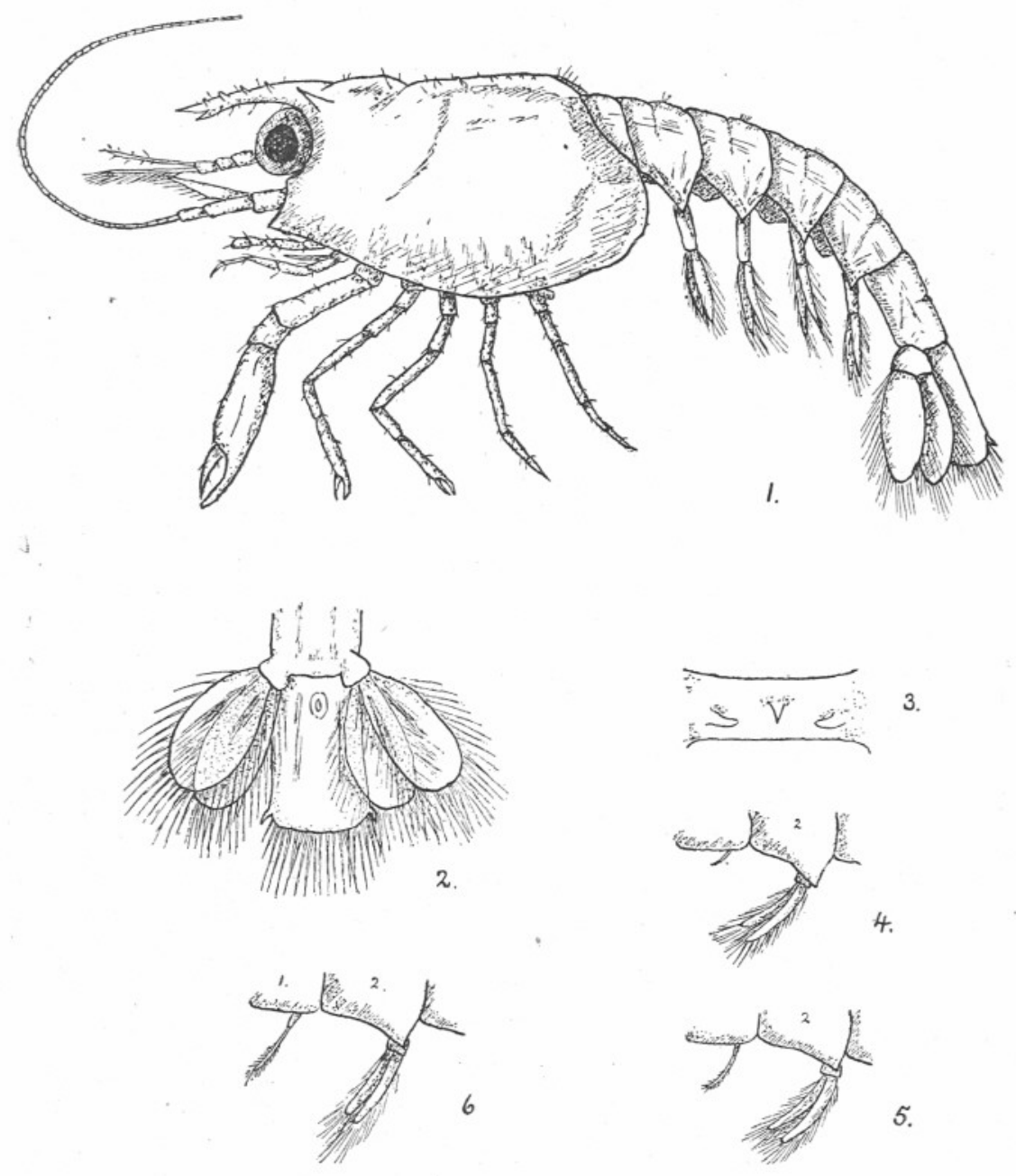

